\title{
Derivative Spectrophotometric determination of Mercury (II) using 3,4-DihydroxyBenzaldehydeTiosemicarbazone(DHBTSC) in presence of micelle medium
}

\author{
M.Mogalali raju ${ }^{1}$, K.Ramakrishna ${ }^{2}$, P.V.Subbarao ${ }^{3}$ \\ ${ }^{1,2,3}$ Department of Chemistry, GITAM Institute of science, GITAM University, Visakhapatnam-530045,A.P. \\ India.
}

\begin{abstract}
A rapid and sensitive method has been developed for the determination of Mercury(II) based on complexation reaction between the metal ion and 3,4,-dihydroxybenzaldehydethiosemicarbazone (DHBTSC) in the presence of non-ionic surfactant Tween-80. The important parameters affecting the analytical procedure were optimized. Absorption maximum for a ternary complex was noted at $375 \mathrm{~nm}$. The reaction was found to be rapid at room temperature and absorbance remained constant for more than 24h. The method obeys Beer's law in the range 5.01 to $50.14 \mathrm{ng} / \mathrm{ml}$. The apparent molar absorptivity of $3.25 \times 10^{5} \mathrm{~L} \mathrm{~mol}^{-1} \mathrm{~cm}^{-1}$ and Sandell's sensitivity $0.06 \mathrm{ng} / \mathrm{ml}$. The effect of foreign ions was tested by taking a constant concentration of metal ion and determining its concentration in the presence of $\geq 100$ folds in excess of foreign ions. The method was successfully used in the determination of Mercury(II) in Sewage waste and Spiked water samples.
\end{abstract}

\section{Introduction}

Mercury is a serious environmental pollutant with toxic effects in all living organisms[1]. It effects on the immune system is potentially harmful, possibly contributing to diseases such as leukemia[2]. It is usually present in natural waters at trace levels[3] . the lakes, rivers and costal waters in the vicinity of industries that utilize mercury in production are important indicators of environmental pollution. The main species of mercury in natural waters to be identified and determined are inorganic mercury $\left(\mathrm{Hg}^{+2}\right)$ and methyl mercury $\left(\mathrm{CH}_{3} \mathrm{Hg}^{+}\right)$. Recent reports estimate total mercury concentration in natural waters to range from 0.2 to $100 \mathrm{ng} \mathrm{L}^{-1}$, while methyl mercury levels are much lower(approximately $0.05 \mathrm{ngL}^{-1}$ )[4].However, mercury in contaminated environmental materials may exist at levels of monograms per liter. The development of analytical methods for the determination of mercury is still a challenge. The determination of low concentration of mercury is a vital task. Therefore, considerable efforts and progress have been carried out to develop accurate, low cost and reliable methods for mercury determination in contaminated samples without any complicated processing steps[5].The most common techniques the pre-concentration should be performed to determine ultra trace $\mathrm{Hg}(\mathrm{II})$. However these procedures could reduce the accuracy of the determination and require, a longer time in handling of sample. Among these pre-concentration techniques, cold vapor atomic absorption spectrometry has widely been used [6-8]. X -ray fluorescence spectrometry (XRF)[9], atomic fluorescence spectrometry ( AFS)[10,11] and spectrophotometer[12-15] have been used to determine $\mathrm{Hg}(\mathrm{II})$ at trace levels. Each of the above techniques has its own merits, but each also shares some of the common problems of poor reproducibility and limited sample adaptability. Among these techniques, visible absorption spectrophotometer represents of the most convenient technique because of the availability of the instrumentation, simplicity speed precision accuracy and low cost.

A series of chromogenic reagents has been reported for mercury (II) determination in different samples [16-20]. Most of these methods are suffered from the lack of sensitivity due to the significant interference of the excess of chromogenic reagent with the analyte at Wavelength. This problems was solved by employing softlewis base such as sulfur ligands. Thiosemicarbazone have been used for spectrophotometric determination because of their good selectivity and sensitivity, although for conventional spectrophotometric analysis in aqueous solutions, the low solubility of these thiosemicarbazone compound and their complex is a significant drawback. This draw back can be over come by adding organic solvent (or) surfactants .

The recent literature on the analytical Applications of the entitled reagent 3,4 dihydroxybenzadehydethiosemcarbazone abbreviated as (3,4-DHB TSC) has revealed no study on the use of reagent for mercury(II) determination.

Therefore, the goals of the present manuscript are focused on the synthesis and spectroscopic characterization(Ur-Vis IR and H NMR, Mass) of the DHBTSC reagent. Morever the stiochiometry of the formed mercury (II)-DHBTSC chelate was elucidated in an attempt to develop and accurate method for the analysis of mercury(II) in different water and sewage samples. 
Recently enhanced sensitivity in spectrophotometer was achieved by utilizing the ability of certain surfactants to sensitize the binary complexes of the metal ion with chromogenic ligands[21,22] sensitization are result of the replacement of acidic protons of the liganded dye molecure by surfactant[23] (or) adsorption of the metalreagent complex on the micelles of the surfactant [24] cationic, anionic and nonionic surfactants are often used to sensitize the metallochromic indicators. In this context, updated surfacactant - sensitized reaction have recently been developed in sepctrophotometr[25-29].

The present study was hence planned to suggest a very simple and reasonably good method for determination of mercury ions at low concentration, using the reported reagent. DHBTSC as binary complex and sensitizing the reagent with Tween 80 as ternary complex using spectrophotometer which is still frequently used because of its low cost and simplicity.

\subsection{Apparatus}

\section{Experimental}

The Absorbance and $\mathrm{pH}$ measurements were made on a Shimadzu UV-visible spectrophotometer ( Model UV -160A) fitted with 1cm Quartz cells and Philips digital pH meter ( model L1 613 respectively.)

\subsection{Reagents and solutions}

2.2.1 Preparation of 3,4-di hydroxybenzldehydethiosemicarbazone( DHBTSC) The Reagent ( DHBTSC) is prepared by the sah and Daniels procedure. $7 \mathrm{~g}$ of 3,4-dihydroxybenzaldehyde(1) was dissolved in $100 \mathrm{~mL}$ of methanol and $4.6 \mathrm{~g}$ of thoisemicarbazide(2) were dissolved in hot water. The two solutions were taken in 250 $\mathrm{mL}$ Erlynmeyer flask and refluxed for $3 \mathrm{hrs}$. pale yellow colored crystals were separated out on cooling. These crystals were collected by filtration and washed several times with hot water and 50 persent methanol. The product(3,4-dihydroxybenzaldehydethiosemicarbazone)(3) (m.p 221-223 ${ }^{\circ} \mathrm{c}$ ) was recrystallisedtwise from boiling methanol and dried in vacuum.<smiles>O=Cc1ccc(O)c(O)c1</smiles>

[1]<smiles>NNC(N)=S</smiles>

[2]<smiles>NC(=S)N/N=C/c1ccc(O)c(O)c1</smiles>

[3]

All chemicals used were of analytical reagents grade or the highest purity available. Double distilled deionized water, which is non-absorbant under ultraviolet radiation, was used throughout. Glass vassals were cleaned by soaking in acidified solutions of $\mathrm{KMnO}_{4}$ or $\mathrm{K}_{2} \mathrm{Cr}_{2} \mathrm{O}_{7}$, followed by washing with concentrated $\mathrm{HNO}_{3}$ and rised several times with deionized water.

2.2.2 Tween-80 solution 1\%. A $100 \mathrm{~mL}$ of Tween-80 solution was prepared by dissolving $1 \mathrm{~mL}$ of pure tween80 in $100 \mathrm{~mL}$ if doubly distilled deionized water, sonicated for $15 \mathrm{~min}$ and diluted with deionized water when it became transparent.

\subsubsection{3,4-Dihydroxybenzaldehydethiosemicarbazone (DHBTSC ) $\left(1 \mathrm{X} \mathrm{10}^{-4} \mathrm{~mol}_{\mathrm{dm}} \mathrm{dm}^{3}\right)$}

A $25 \mathrm{~mL}$ solution was prepared by dissolving $0.0528 \mathrm{~g}$ of recrystalised sample in dimethylformamide and it was suitably diluted to get the required concentration.

\subsubsection{Mercury (II) standared solution $\left(4.99 \times 10^{-3} \mathrm{~mol} / \mathrm{dm}^{3}\right)$}

A $100 \mathrm{~mL}$ stock solution $(1 \mathrm{mg} / \mathrm{mL})$ of divalent mercury was prepared by dissolving $135 \mathrm{mg}$ of mercuric chloride (Merck, Darmstadt) in deionized water containing $1-2 \mathrm{~mL}$ of nitric acid $(1+1)$. Aliquots of this solution were standardized with EDTA using XylenolOreange as an indicator. More dilute standard solution were prepared from this stock solution, as and when required.

\subsubsection{Procedure}

Direct spectrophotometry

In each of set of different $10 \mathrm{~mL}$ volumetric flasks, $5 \mathrm{ml}$ of buffer solution ( $\mathrm{pH} 6.5), 1 \mathrm{~mL}$ of DHBTSC $\left(1 \times 10^{-3} \mathrm{~mol} / \mathrm{dm}^{3}\right)$ and various volumes of $1 \times 10^{-6} \mathrm{~mol} / \mathrm{dm}^{3}$ mercury(II)finally added $1 \mathrm{~mL}$ of $1 \%$ Tween- 80 and $\mathrm{f}$ solution were taken and made up to the mark with double distilled water. The absorbance was 
measured at $375 \mathrm{~nm}$ against the reagent blank. The calibration plot was prepared by plotting the absorbance against the amount of mercury(II).

Second order derivative spectrophotometry

For the above solutions, second order derivative spectra were recorded with a scan speed of fast (nearly $2400 \mathrm{~nm} \mathrm{~min}{ }^{-1}$ ); slit width of $1 \mathrm{~nm}$ with nine degrees freedom, in the wavelength range 390-510 nm. The derivative amplitude measured at wavelength $440 \mathrm{~nm}$ and plotted against amount of mercury(II) to obtain the calibration.

The calibration grph follows the straight line equation $\mathrm{Y}=\mathrm{aC}+\mathrm{b}$; where $\mathrm{C}$ is the concentration of the solution, $\mathrm{Y}$ is measured absorbance or peak or vally height and $\mathrm{a}$ and $\mathrm{b}$ are constants. By substituting the corresponding experimental data substituted in the above equation, the calibration equations were calculated as $\mathrm{A}_{375}=0.0189 \mathrm{C}-0.0494$ for zero order method, $\mathrm{A}_{440}=0.014 \mathrm{C}+0.036$ for second order derivative method.

\subsection{Factors affecting the absorbance}

\section{Results and Discussion}

\subsubsection{Absorption spectra}

The absorption spectra of the mercury (II)-3,4-DHBTSC system in a micellar medium were recording using a spectrophotometer. The absorption spectra of the $\mathrm{Hg}(\mathrm{II})-3,4-\mathrm{DHBTSC}$ is a symmetric curve with the maximum absorbance at $375 \mathrm{~mm}$ and an average molar absorption coefficient of $3.25 \times 10^{5} \mathrm{~L} \mathrm{~mol}^{-1} \mathrm{~cm}^{-1}$ (Fig. 1). The reagent blank exhibited negligible absorbance, despite having a wavelength in the same region. In all instances, measurements were made at $375 \mathrm{~nm}$ against a reagent blank.

3.1.2 Effect of surfactant: of the various surfactants [nonionic\{poly oxyethylenedodecylether(Brij -35), Polyoxyethylenesorbitanmonoplamitate ( Tween-40), Polyoxyethylenesorbitanmoni-oleate(Tween-80), Triton$\mathrm{X}-100\}$; cationinc [ cetyltrimethylamoniumbromite(CTAB) \} : and anionic \{ cetlpridinium chloride (CPC), sodium dedecy sulfate SDS $\}$ studied. Tween-80 was found to be the best surfactant for the system. In a $1 \%(\mathrm{~V} / \mathrm{L})$ Tween-80 medium however, the maximum absorbance was observed hence, a $1 \%(\mathrm{~V} / \mathrm{L})$ Tween-80 solution was used in the determination procedure.

Different volumes of $1 \%(\mathrm{~V} / \mathrm{L}) \mathrm{Ttween}-80$ were added to a fixed metalion concentration, and the absorbance was measured according to the standard procedure. It was observed that at $20.05 \mathrm{ng} / \mathrm{ml} \mathrm{Hg}$-chelate methal.0.25$1.75 \mathrm{~mL}$ of $1 \%(\mathrm{~V} / \mathrm{V})$ Tween-80 produced a contestant absorbance of the Hg-chelate(Fig. 2). A greater Excess of Tween-80 were not studied. For all subsequent measurements, $1 \mathrm{~mL} 1 \%(\mathrm{~V} / \mathrm{V})$ Tween-80 was added.

\subsubsection{Effect of Acidity}

The absorbance of the complex reaches a maximum over a $\mathrm{pH}$ range of 6.0 to 6.8 . The higher $\mathrm{pH}$ values may lead to hydrolysis of $\mathrm{Hg}$ (II) -3,4-DHBTSC system. The absorbance was at a maximum and constant when a $10 \mathrm{ml}$ of solution $\left(1 \mathrm{mgL}^{-1}\right.$; path length ,1) contained 1-7 mL ( pH6.5) of acidic buffer at room temperature $(25 \pm 5 \mathrm{c})$. Outside this range of acidity, the absorbance decreased (Fig. 3) . For all subsequent measurements $5.0 \mathrm{ml}$ (pH 6.5)acidic buffer was added.

\subsubsection{Effect of time}

The reaction is very fast. Constant maximum absorbance was obtained just after dilution to volume, and remained strictly unaltered $24 \mathrm{~h}$.

\subsubsection{Effect of reagent concentration:}

Different molor excess of 3,4 -DHBTSC were added to a fixed metal -ion concentration, and the absorbances were measured according to the standard procedure. It was observed that at $20.05 \mathrm{ng} / \mathrm{ml} \mathrm{Hg} \mathrm{metal}($ optical path lenth , $1 \mathrm{~cm}$ ) reagent molar ratios 1:10 and 1:100 produced a constant absorbance of the $\mathrm{Hg}$ (II)Chelate(Fig. 4) . A greater excess of the reagent was not studied. For all subsequent measurement $1 \mathrm{~mL}$ of $1 \mathrm{X} 10^{-3} \mathrm{~mol} / \mathrm{dm}^{3} 3,4-$ DHBTSC reagent was added.

\subsubsection{Calibration graph (Beers Law and sensitivity)}

The Calibration curve for the determination of mercury has been constructed (Fig. 5) using the optimum experimental conditions. The straight line calibration curve indicates that Beers' law is obeyed at least over a range of 5.01 to $50.14 \mathrm{ng}$ of mercury per $10 \mathrm{~mL}$.Linear regression analysis of the calibration curve gives a correlation coefficient of 0.9998 . The apparent molar absorptivity $\left(\epsilon_{375}\right)$ calculated from the slop of regression line is $3.25 \times 10^{5} \mathrm{~L} \mathrm{~mol}^{-1} \mathrm{~cm}$-1The Sandell's sensitivity( concentration for 0.001 absorbance unit) was found to be $0.06 \mathrm{ng} \mathrm{cm}^{-2}$. 


\subsubsection{Effect of foreign ions :}

The effect of various foreign ions that are generally associated with mercury(II) on the determination under optimum conditions developed was studied and the results are presented in Table 1. Cations like Ba(II), $\mathrm{Sr}(\mathrm{II})$ and $\mathrm{U}(\mathrm{VI})$ do not have any effect on the complex of $\mathrm{Hg}(\mathrm{II})$-DHBTSC, when present up to 4,700 $\mu \mathrm{g}$, Zinc

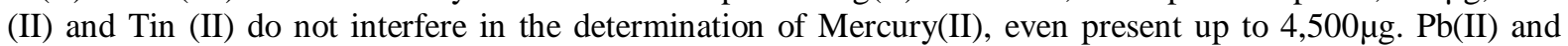
$\mathrm{Mn}$ (II) can be tolerated up to $3,400 \mu \mathrm{g}$. $\mathrm{Fe}(\mathrm{III}), \mathrm{Cu}(\mathrm{II})$ and $\mathrm{Co}$ (II) interference in the determination of Mercury(II), even when present in trace amounts

\subsubsection{Composition of the Metal-Reagent complex}

Jobs method of continous vaitaion( Fig .6) and the molor - ratio method were applied to ascertain the stoichiometeric composition of the complex. A Hg -3,4-DHBTSC(1:2) complex was indicated by both methods. The stability constants was determined by Jobs Method as $6.82 \times 10^{11}$.

\subsection{Applications:}

The Present method was successfully applied to the determination of mercury in sewage waste and spiked water samples.

\subsubsection{Determination of mercury(II) in sewage water}

The proposed method was applied for the determination of mercury(II) in sewage water collected in different parts in Visakhapatnam city.10 g of the dried sample(sewage waste) was weighed and brought into solution by dry ash method. The results are shown in Table 2 . The results showed that the concentration of

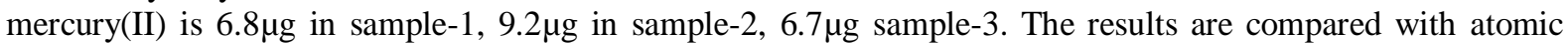
absorptionspectroscopy(AAS) and they are found to be in good agreement.

\subsubsection{Analysis of spiked water samples}

The developed method was applied for the determination of Mercury(II) in spiked water samples. The recovery of mercury(II) from spiked water sample was examined using the general procedure,the results are given in Table 3. Showing that the developed method is applicable to analyse spiked water sample with the percentage recovery for mercury is 99.8 This method was applicable for the analysis of real water samples.

\subsection{Second order derivative method}

The second order derivative curve recorded (Fig. 7) for experimental solution showed the derivative amplitude were measured at $440 \mathrm{~nm}$ (peak) for different concentrations of Mercury(II) and plots were made between the amount of $\mathrm{Hg}(\mathrm{II})$ and the derivative amplitude. The plots were linear and obeyed Beer`s law in the range $4.06-16.04 \mathrm{ng} / \mathrm{mL}$ at $440 \mathrm{~nm}$ respectively.

\subsection{Comparison of results}

The analytical characteristics of the zero and second order derivative methods in the present investigations for Mercury(II) were copared and present in Table 4. The results in this table reveal that second order derivative method is more sensitive and selective than the zero order method.

The sensitivity of the zero method in the present investigations was compared with those of some reported methods and presented in Table 5

\section{Conclusion}

This method offers several interesting features such as simplicity, rapidity, and low cost besides sensitivity. The number of associated elements do not interfere in the determination. The selectivity of the reagent is also improved by the use of suitable masking agents to suppress the interference of metal ions like $\mathrm{Fe}(\mathrm{III}), \mathrm{Cu}(\mathrm{II})$, and $\mathrm{Co}(\mathrm{II})$. Hence the proposed method is recommended for the determination of Mercury(II) with DHBTSC in presence of micells by spectrophotometric method, at minor and trace levels, besides its use for analysis of real samples such as industrial effluents.

\section{References}

[1] M.Yoshid,.A.Stoh,A. shimoda, :Y. Sumi : C.Tohyama,Toxicology, 139, 1999,129-136.

[2] M.Saber- Tehvani,:M.H.Givianred,:H. Haswmi-Moghaddam, Talanta, 712007 , 1319-1325.

[3] J.L.Manzoori,M.H..Sorovaddin, A.M. Hojishabani, J. Anal. At. Sepctrom, 13, 1998, , 305-308.

[4] R.M.Blanco, M.T Villanueva, J.E.S Uria, A.S Medel, Anal.Chim. Acta, 4192000 , 137-144.

[5] M.S.Hosseini, H.Hashemi - Moghaddam, Talanta, 67, 2005, 555-559,

[6] S.Rio-Segade,C. Bendicho, Spectrochim.Acta Part B, 54, 1999, 1129-1139.

[7] W.E.Doering, R.R.James. R.T.Echols, Fresen. J. Anal. Chem., 368, 475-479.

[8] M. A. H. Hafez, I.M.M. Kenawy, M.A. Akl, R.R Lashein, Talanta 53, 2001,749-760.

[9] L.Bennun, J.Gomez, Spectrochim.Acta, 52, 1997, 1195-1200. 
[10] V.Fernadez-Perez, L.E.Garcia-Ayuso, M.D.Luquede Castro, Analyst, 125. 2000, 317-322.

[11] L.Rahman, W.T.Corns, D.W.Bryce, P.B.Stockwell, Talanta, 52, 2000, 833-843

[12] B.Raman, V.M.Shinde, Analyst, 115, 1990, 93-98.

[13] M.Kamburova,Talanta, 40, 1993, 719-723.

[14] D.C.Nambiar, N.N.Patil, V.M.Shinde, Fresen. J. Anal. Chem., 360, 1998, 205-207.

[15] E.Y.Hashem, Spectrochim. Acta, 58A, 2002, 1401-1410.

[16] S.Suresha, M.F Silwadi, A.A Syed, .Int J Environ AnlaChem, 82 ,2002, 275- 289.

[17] A.Y. El-Sayed, Anal. Lett, 31, 1998, 1905-1916.

[18] E.B.Sandell, Colorimetric Method of Analysis, WileyInterscience(New York, 1959).PP. 445.

[19] Xiao-Ling He, Yong-Qic Wang, K.Q Ling, Talanta, 72, 2007, 747-754

[20] S.Chatterjee, A.Pillai, V.K. Gupta, Talanta, 57, 2002, 461-465

[21] M.D.Bezerra, M.A.Z. Arruda, S.L.C.Ferreira, Appl. Spectrosc. Rev, 40, 2005, 269-299

[22] T.PrasadRao, M.L.P.Reddy, A. RamalingomPillai, Talanta, 46, 1998, 765-813.

[23] T.PrasadRao, T.V.Ramakrishna, Bull. Chem. Soc. Jpn, 53, 1980, 2380.

[24] M.T.MZaki, A.Y. Elsayed, Anal.Lett. 28, 1995, 1525.

[25] S.Kundu, S.K.Ghosh, M.Mandal,T.pal, A.Pal, Talanta, 58, 2002, 935-942.

[26] M.Ghaedi,E.Asadpour,A.Vafaie,Spectrochim. Acta A Mol. BiomolSpectrosc, 63, 2006, 182-188.

[27] M.Ghaedi, Spectrochim. Acta A Mol. BiomolSpectrosc, 66, 2007, 295-301.

[28] M.Ghaedi, A.Daneshfar, A.Shokrollahi, H.Ghaedi, F.ArvinPili, Ann Chim(Roma), 97, 2007, 971-982.

[29] A.Shokrollahi, M.Ghaedi, M.S.Niband, H.R.Rajabi, J. Hazard. Mater, 151, 208, 642-648.

[30] M.V.R.Murthy,S.M.Khopkar,Bull. Chem. Soc. Jpn. 50, 1997,738-741.

[31] M.Tsubouchi, Bull. Chem. Soc. Jpn. 43, 1970,2812.

[32] J.R.Mudakavi,Analyst,109, 1984, 1577-1579.

[33] B.Saad,S.M.Sultan, Talanta, 42, 1994,1349-1354

[34] M.J.Ahmed,M.S.Alam, Spectroscopy, 17, 2003,45-52.

[35] A.Hamaz, A.S.Bashammakh, A.A.AL-Sibaai, J.HazardousMaterials 178, 2010, $287-292$.

Table 1. Effect of Foreign ions in (30.08 ng/mL) amount of Mercury(II)

\begin{tabular}{cc}
\hline \hline Ions & Tolerance limit $(\mu \mathrm{g})$ \\
\hline \hline $\mathrm{Ba}^{+2}, \mathrm{Sr}^{+2}, \mathrm{U}^{+6}$ & 4700 \\
$\mathrm{Zn}^{+2}, \mathrm{Sn}^{+2}$ & 4500 \\
$\mathrm{~Pb}^{+2}, \mathrm{Mn}^{+2}$ & 3400 \\
$\mathrm{Fe}^{+3}, \mathrm{Cu}^{+2}, \mathrm{Co}^{+2}$ & 3100 \\
$\mathrm{~F}^{-}, \mathrm{Cl}^{-}, \mathrm{CH}_{3} \mathrm{COO}^{-}$, & 5500 \\
$\mathrm{I}^{-}, \mathrm{SO}_{4}^{-2}, \mathrm{Br}^{-}, \mathrm{HCO}_{3}^{-}, \mathrm{SCN}^{-}$ & 5000 \\
\hline \hline
\end{tabular}

Table 2. Determination of $\mathrm{Hg}(\mathrm{II})$ in spiked water samples

\begin{tabular}{|c|c|c|c|c|}
\hline \multirow[t]{2}{*}{ P.No } & \multirow{2}{*}{$\begin{array}{c}\text { Amount of metal ion } \\
\text { added }(\mu \mathrm{g})\end{array}$} & \multicolumn{2}{|c|}{ Metal ion found } & \multirow{2}{*}{$\begin{array}{l}\text { Recovery (\%) } \\
\text { Present method }\end{array}$} \\
\hline & & $\begin{array}{c}\text { Present } \\
\operatorname{method}^{*}(\mu g)\end{array}$ & $\begin{array}{l}\text { AAS } \\
\text { method }\end{array}$ & \\
\hline 1 & 30 & 29.6 & 29.7 & 99.0 \\
\hline 2 & 60 & 59.5 & 59.8 & 99.3 \\
\hline 3 & 90 & 88.7 & 89.8 & 97.2 \\
\hline 4 & 120 & 119.4 & 119.7 & 99.3 \\
\hline 5 & 150 & 149.3 & 149.8 & 99.0 \\
\hline
\end{tabular}

*Average value of three determination

Table 3. Determination of mercury(II) in Sewage waste samples

\begin{tabular}{|c|c|c|c|c|}
\hline \multirow[t]{2}{*}{ S.No } & \multirow[t]{2}{*}{ Area of sewage waste } & \multicolumn{2}{|c|}{ Metal ion found } & \multirow{2}{*}{$\begin{array}{l}\text { Recovery (\%) } \\
\text { Present method }\end{array}$} \\
\hline & & $\begin{array}{c}\text { Present } \\
\operatorname{method}^{*}(\mu g)\end{array}$ & $\begin{array}{c}\text { AAS } \\
\text { method }\end{array}$ & \\
\hline 1 & Steel plant area & 6.7 & 7.0 & 99.3 \\
\hline 2 & HPCL area & 9.5 & 9.8 & 99.3 \\
\hline 3 & $\begin{array}{l}\text { Hindustan Zinc Ltd. } \\
\text { Area }\end{array}$ & 6.1 & 6.9 & 98.6 \\
\hline
\end{tabular}


Table 4. Comparison of results of Mercury(II)

\begin{tabular}{lll}
\hline \hline Parameter & Zero order & Second derivative \\
\hline \hline & & \\
Analytical wave length(nm) & 375 & 440 \\
Beer`s law range(ng/mL) & $5.01-50.14$ & $4.06-16.04$ \\
Angular coefficient(m) & 0.0189 & 0.014 \\
Y-ntercept(b) & 0.494 & 0.036 \\
Correlation coefficient(r) & 0.9998 & 0.998 \\
Standared deviation(s) & $0 . .088$ & 0.053 \\
\hline \hline
\end{tabular}

Table 5. Comparison with other methods

\begin{tabular}{|c|c|c|c|c|}
\hline Reagent/Ref & $\overline{\lambda \lambda_{\max }}$ & $\overline{\mathrm{pH}}$ & $\begin{array}{l}\text { Linear } \\
\text { range }\end{array}$ & $\begin{array}{l}\text { Molar absorptivity(L } \\
\left.\mathrm{mol}^{-1} \mathrm{~cm}^{-1}\right)\end{array}$ \\
\hline Thiobenzoylacetone/[30] & 345 & 4 & $0.6-12 \mu \mathrm{g}$ & $1.7 \times 10^{4}$ \\
\hline Variamine Blue/[31] & 605 & $2.5-4$ & $0.64-4.4 \mu \mathrm{g}$ & $4 \times 10^{4}$ \\
\hline Phenanthroline and eosin/[32] & 550 & 4.5 & $0.2-1.2 \mu \mathrm{g}$ & $8 \times 10^{4}$ \\
\hline $\begin{array}{l}\text { Thiacrown ether and } \\
\text { Bromocresol Green/[33] }\end{array}$ & 420 & --- & $0.5-12 \mu \mathrm{g}$ & \\
\hline Diphenylthiocarbazone/[34] & 488 & Acidic media & $0.1-25 \mu \mathrm{g}$ & $2.5 \times 10^{4}$ \\
\hline HOTT/[35] & 505 & 4-6 & $0.2-2 \mu \mathrm{g}$ & $4 \times 10^{4}$ \\
\hline Present work & 375 & 6.5 & $\begin{array}{l}5.01- \\
50.4 \mathrm{ng}\end{array}$ & $3.25 \times 10^{5}$ \\
\hline
\end{tabular}

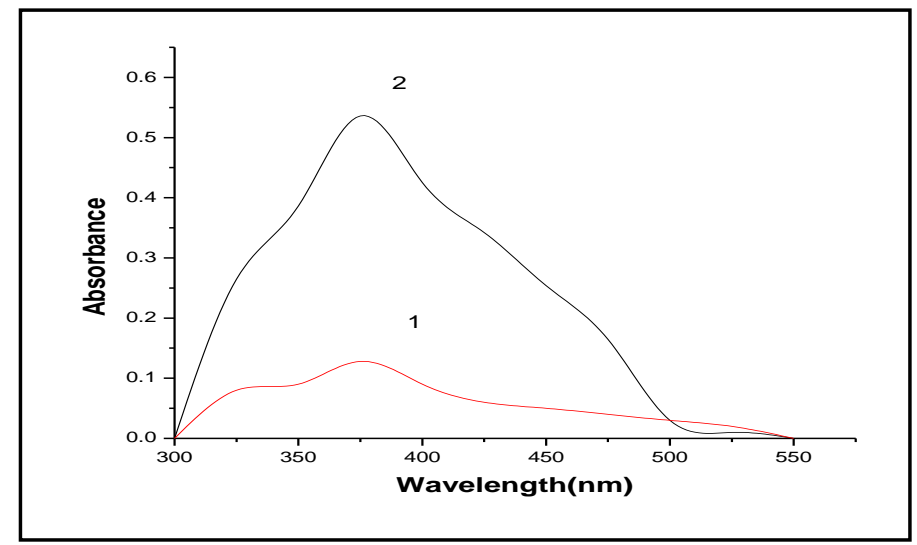

Fig. 11 and 2 absorption spectra of reagent blank and $\operatorname{Hg}(\mathrm{II})$-DHBTSC system $\left(\lambda_{\max }=375 \mathrm{~nm}\right)$ in nonionic micellar medium

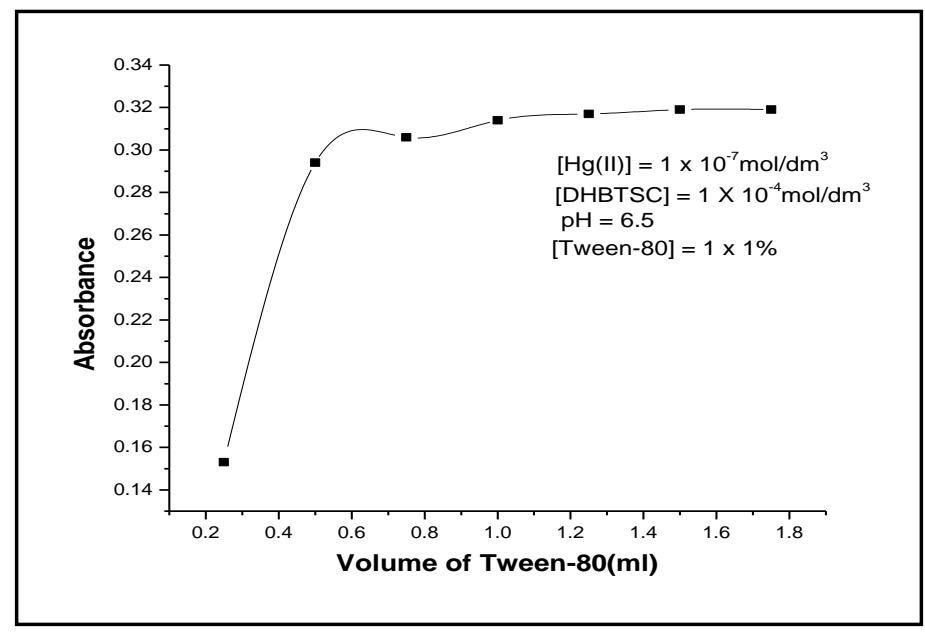

Fig. 2 Effect of surfactant on the absorbance of the Mercury(II)-DHBTSC system 


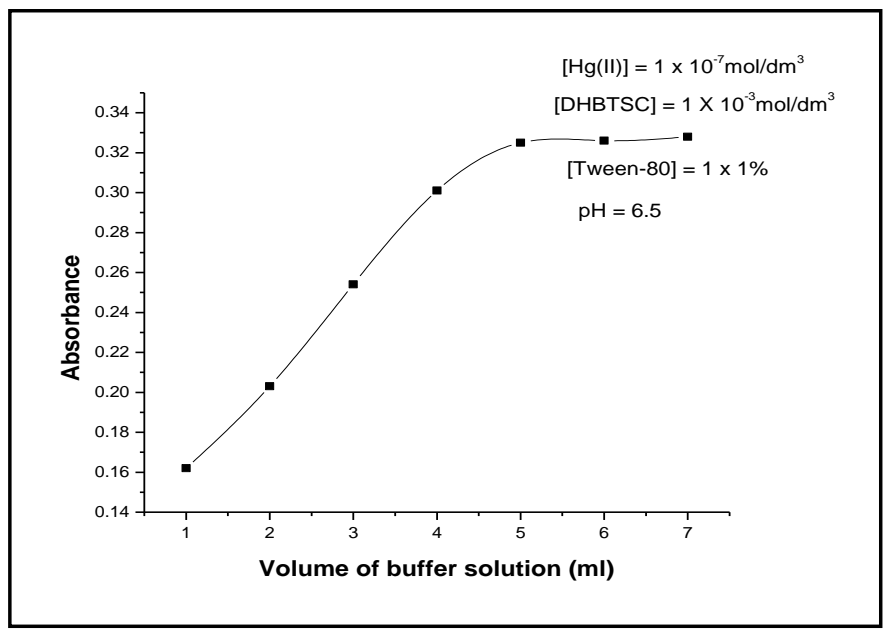

Fig. 3 Effect of Buffer solution on the absorbance of the Mercury(II)-DHBTSC system

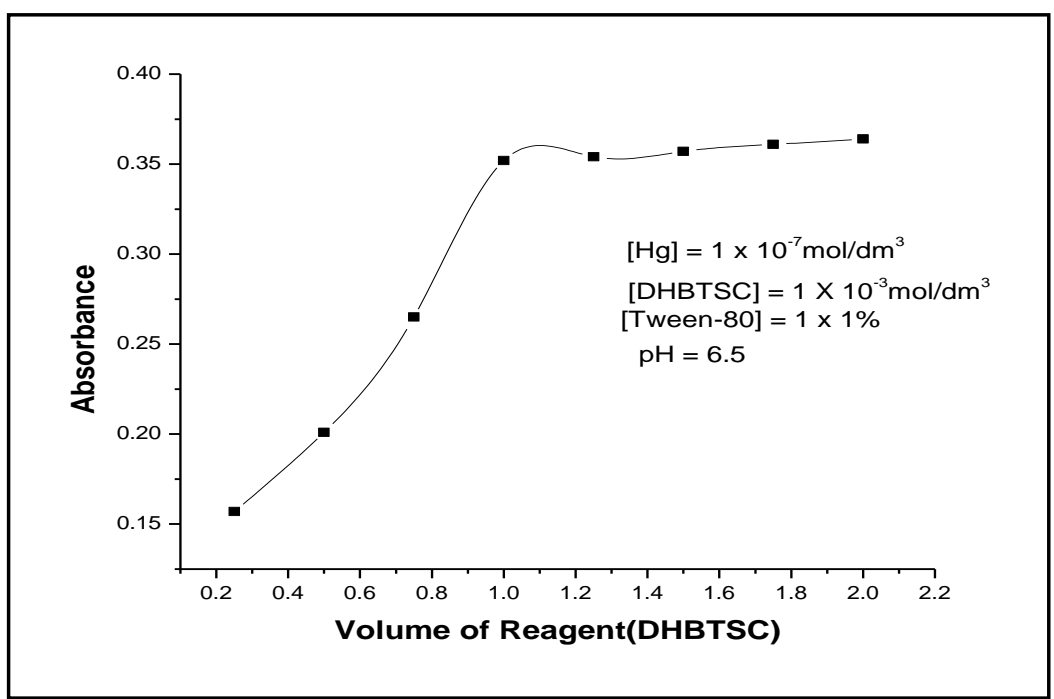

Fig. 4 Effect of reagent(DHBTSC) on the absorbance of the Mercury(II)-DHBTSC system.

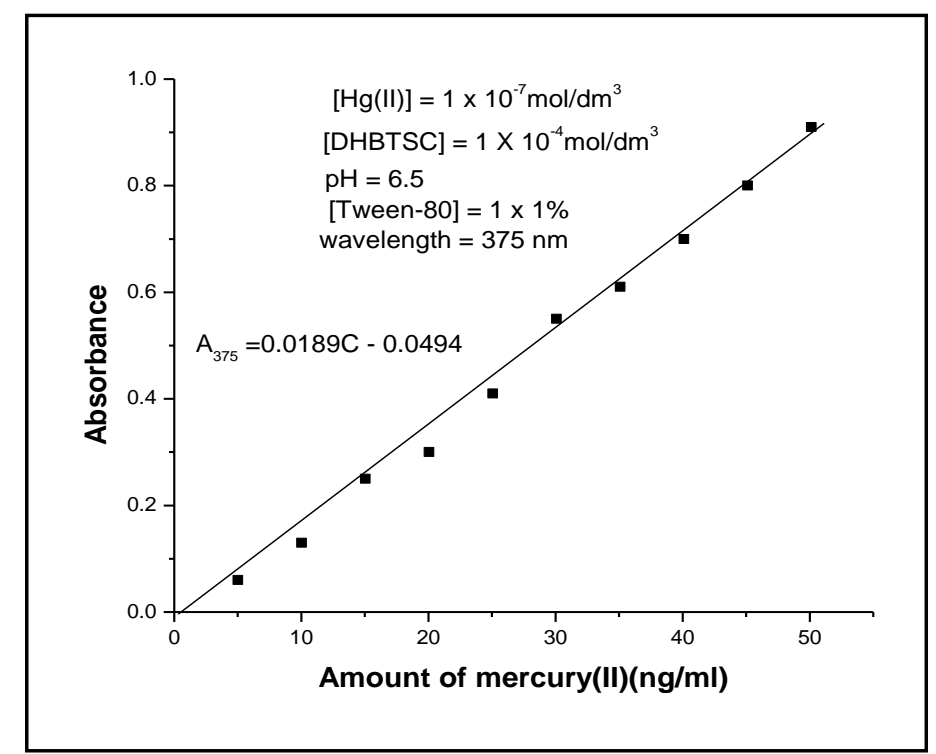

Fig. 5 Calibration graph 


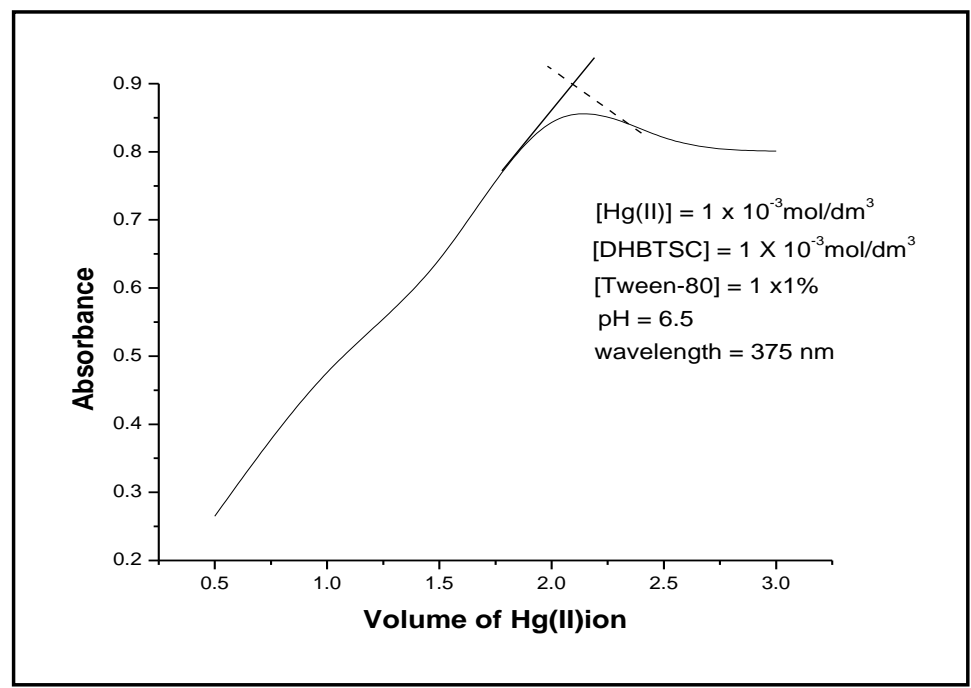

Fig. 6 Job`s curve

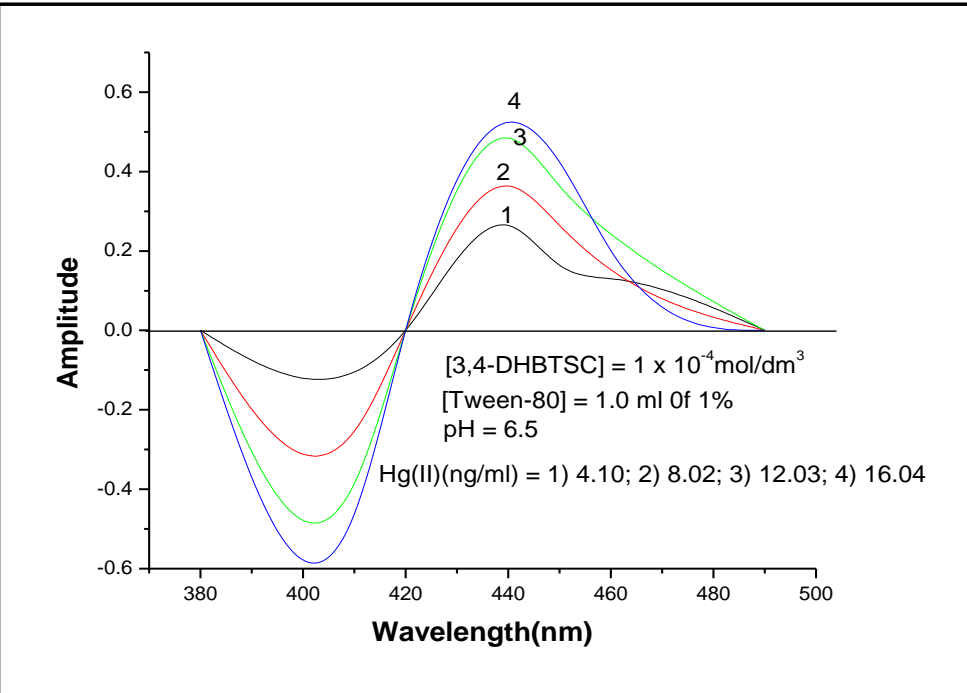

Fig. 7 Second derivative spectra of Mercury(II)-DHBTSC Vs reagent blank. 